NBSIR 84-2921

\title{
Structural Reliability Fundamentals and Their Application to Offshore Structures
}

Emil Simiu

U.S. DEPARTMENT OF COMMERCE

National Bureau of Standards

Center for Building Technology

Gaithersburg, MD 20899

and

Charles E. Smith

Technology Assessment and Research Branch

Minerals Management Service

U.S. Department of the Interior

Reston, VA 22091

September 1984

Prepared for:

Minerals Management Service

I.S. Department of the Interior

100 leston, VA 22091

.456

34-2921 



\section{STRUCTURAL RELIABILITY FUNDAMENTALS AND THEIR APPLICATION TO OFFSHORE STRUCTURES}

Emil Simiu

U.S. DEPARTMENT OF COMMERCE

National Bureau of Standards

Center for Building Technology

Gaithersburg, MD 20899

and

Charles E. Smith

Technology Assessment and Research Branch

Minerals Management Service

U.S. Department of the Interior

Reston, VA 22091

September 1984

Prepared for:

Minerals Management Service U.S. Department of the Interior Reston, VA 22091

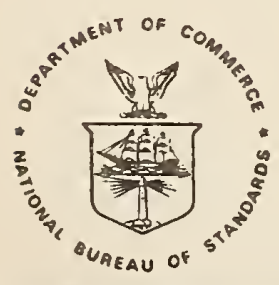

U.S. DEPARTMENT OF COMMERCE, Malcolm Baldrige, Secretary NATIONAL BUREAU OF STANDARDS, Ernest Ambler, Director 

TABLE OF CONTENTS

$\underline{\text { Page }}$

1. InTRODUCTION $\ldots \ldots \ldots \ldots \ldots \ldots \ldots \ldots \ldots \ldots \ldots \ldots \ldots \ldots \ldots \ldots \ldots \ldots \ldots \ldots \ldots$

2. NOMINAL FAILURE PROBABILITIES, SAFETY INDICES, AND LOAD AND RESISTANCE FACTORS $\ldots \ldots \ldots \ldots \ldots \ldots \ldots \ldots \ldots \ldots \ldots \ldots \ldots \ldots \ldots \ldots \ldots$

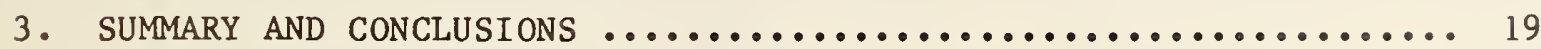

4. REFERENCES ....................................... 20 


\section{LIST OF TABLES}

$\underline{\text { Page }}$

Table 1. Probabilities of Failure of Four Members Corresponding to Various Distributions of the Variables ................ 14

\section{LIST OF FIGURES}

Figure 1. Index $\beta$ for member with random load and deterministic

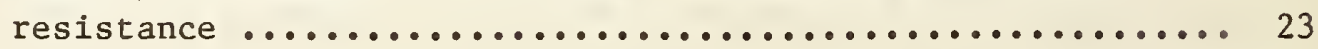

Figure 2. Index $\beta$ for member with random load and random resistance . 24 Figure $3 . \quad$ Index $\beta$ in space of variables $r_{r}, u_{r} \ldots \ldots \ldots \ldots \ldots \ldots \ldots$

Figure 4. Failure boundaries for members I and II ............. 26

Figure 5. Probability density function $f_{p}\left(r_{r}\right) \ldots \ldots \ldots \ldots \ldots \ldots$ 


\section{INTRODUCTION}

The objective of structural reliability is to develop design criteria and verification procedures aimed at ensuring that structures built according to specifications will perform acceptably from a safety and serviceability viewpoint. This objective could in principle be achieved by meeting the following requirement: failure probabilities (i.e., probabilities that structures or members will fail to satisfy certain performance criteria) must be equal to or less than some benchmark values referred to as target failure probabilities.a Such an approach would require $[2,13]$ :

1. The probabilistic description of the loads expected to act on the structure.

2. The probabilistic description of the physical properties of the structure which affect its behavior under loads.

3. The physical description of the limit states, i.e., the states in which the structure is unserviceable (serviceability limit states) or unsafe (ultimate limit states). Examples of limit states include: excessive deformations (determined from functional considerations); excessive accelerations (determined from studies of equipment performance, or from ergonomic studies on user discomfort in structures experiencing dynamic loads); specified levels of nonstructural damage; structural collapse.

4. Load-structural response relationships covering the range of responses from zero up to the limit state being considered.

5. The estimation of the probabilities of occurrence of the various limit states (i.e., of the failure probabilities), based on the elements listed in items 1 through 4 above and on the use of appropriate probabilistic and statistical tools.

6. The specification of maximum acceptable probabilities of occurrence of the various limit states (i.e., of target failure probabilities).

The performance of a structure would be judged acceptable from a safety or serviceability viewpoint if the differences between the target and the failure probabilities were either positive (in which case the structure would be overdesigned) or equal to zero.

a An alternative statement of this requirement is that the reliabilities corresponding to the various limit states must be equal to or exceed the respective target reliabilities (reliability being defined as the difference between unity and the failure probability). 
The approach just described is seldom applicable in practice. Owing to physical and probabilistic modeling difficulties and to the absence of sufficient statistical data it seldom is possible to provide confident probabilistic descriptions of the loads, particularly within the loading range corresponding to ultimate limit states. Comprehensive probabilistic descriptions of the relevant physical properties of the structure are frequently not available. In some cases limit states are difficult to define quantitatively, particularly with regard to serviceability. Difficulties may also arise in attempting to describe relationships between loading and structural response that involve material and/or geometric nonlinearities or contributions by nonstructural elements to the total structural capacity. For many realistic structures (e.g., redundant offshore structures subjected to wind and wave effects) the estimation of failure probabilities can be analytically unfeasible or computationally prohibitive, at least in the present state of the art. A further difficulty is due to the iterative nature of the design process and the consequent need to perform a reliability check after each step of the iterative design. Finally, there are few agreed upon values of target failure probabilities, particularly for. limit states involving loss of life, as opposed to mere economic loss.*

The reliability analyst is therefore forced to accept various compromises. In practice, in the absence of sufficient data and of proved probabilistic and physical models, it may be necessary to use conservative models, or models based at least in part on subjective belief. In addition, definitions of limit states may have to be adopted on the basis of computational convenience, rather than on physical grounds. (For example, ultimate limit states are defined in most cases as the collapse of individual members, rather than as the collapse of the structure as a whole; ${ }^{*}$ member collapse is in certain cases conventionally defined as the attainment of the yield stress at the most highly stressed section of the member, even though this does not usually entail physical collapse.) Finally, to simplify the computations, various approximations concerning the mechanical and probabilistic behavior of the structure may have to be used.

Estimates of nominal (or "notional") failure probabilities are thus obtained that can differ-in certain instances significantly--from the "true" probabilities. However, if there are grounds to believe that the ratios of nominal to "true" probabilities for two given designs do not differ significantly, the two designs may be compared from a reliability viewpoint on the basis of the respective nominal, rather than "true", probabilities. It would, of course, be desirable to establish target (i.e., maximum acceptable) nominal failure probabilities. Attempts are made to infer target nominal failure probabilities

* For questions pertaining to safety goals for the operation of nuclear power plants, see reference 1 .

** In recent years a number of studies concerned with structural systems have been reported $[2,3,4,5,6,7]$. However the practical usefulness of such studies remains limited, particularly as far as ocean engineering applications are concerned. 
from the reliability analysis of exemplary designs, i.e., designs that are regarded by professional consensus as acceptably but not overly safe. Such inferences are part of the process referred to as safety calibration against accepted practice.

While there are instances where such a process can be carried out successfully, difficulties arise in many practical situations. For example, structural reliability calculations suggest that current design practice as embodied in the American National Standard A58.1 [8] and other building standards and codes is not risk-consistent. In particular, estimated reliabilities of members designed in accordance with current practice are considerably lower for members subjected to dead, live, and wind loads than for members subjected only to dead and live loads [9, 13, 17], especially when the effect of wind is large compared to the effect of dead and live loads.* Whether these differences are real or only apparent, $1 . e$. , due to shortcomings of current structural and reliability analyses, remains to be established. Thus, it is not possible in the present state of the art to determine whether it is the lower or the higher estimated reliabilities that should be adopted as target values.

In spite of both theoretical and practical difficulties, structural reliability tools can in a number of cases be used to advantage in design and for code development purposes. The objective of this report is to present a review of fundamental topics in structural reliability as applied to individual members, which are potentially applicable to ocean engineering problems. These topics include: the estimation of failure probabilities; safety indices; and safety (or load and resistance) factors.

* The earliest justification of current design practice with respect to wind loading was traced by the authors to Fleming's 1915 monograph Wind Stresses [10], which states: "Maximum wind loading comes seldom and lasts but a short time. The working stresses used for the loading may therefore be increased by $50 \%$ above those used for ordinary live- and dead-loads." 
2. NOMINAL FAILURE PROBABILITIES, SAFETY INDICES, AND LOAD AND RESISTANCE FACTORS

The estimation of nominal failure probabilities ${ }^{a}$ is an essential task of structural reliability. Safety indices are, at least in theory, measures of failure probabilities. The use of load and resistance factors in design criteria is intended to ensure that the members to which the criteria are applied have acceptable failure probabilities within any specified period of interest ( $\mathrm{e} . \mathrm{g}$. one year, or the lifetime of a structure).

Modeling of Loads as Random Processes and Random Variables

Quantities that vary continuously and randomly with time (e.g•, the wind speed, the wind velocity vector, or the wave height at a given location) can be modeled as random processes. Quantities that are constant in time, (e.g., the dead weight), or whose variation in time follows a deterministic law, can be modeled more simply as random variables.

In problems involving combinations of two or more randomly time-dependent loads, it is in general necessary to estimate failure probabilities by resorting to models and techniques drawn from the theory of random processes. If the system being considered depends, in addition to the randomly time-dependent loads, upon the random variables, $\mathrm{x}_{1}, \mathrm{x}_{2}, \ldots \mathrm{x}_{\mathrm{m}}$, estimates of failure probabilities $\mathrm{P}$ (failure $\mid \mathrm{X}_{1}, \mathrm{X}_{2}, \ldots \mathrm{X}_{\mathrm{m}}$ ) are obtained which are conditional upon the values $\mathrm{x}_{1}, \mathrm{x}_{2}, \ldots \mathrm{x}_{\mathrm{m}}$ taken on by these variables. The probability of failure of the structure, $P_{f}$, is then estimated by applying the theorem of total probability as follows:

$$
P_{f}=\int P\left(\text { failure } \mid x_{1}, x_{2}, \ldots x_{k}\right) f_{X_{1}}, x_{2}, \cdots x_{k}\left(x_{1}, x_{2}, \ldots x_{k}\right) d x_{1} d x_{2} \ldots d x_{k}
$$

where $\mathrm{f}_{\mathrm{X}_{1}}, \mathrm{x}_{2}, \ldots \mathrm{x}_{\mathrm{k}}\left(\mathrm{x}_{1}, \mathrm{x}_{2}, \ldots \mathrm{x}_{\mathrm{k}}\right)$ = joint probability density function of $\mathrm{X}_{1}, \mathrm{X}_{2}, \ldots \mathrm{X}_{\mathrm{k}}$. For treatments of load combination problems based on random process representations see references 11 and 12 .

In problems involving only one randomly time-dependent parameter, $\zeta(t)$, the question of combining time-dependent random processes no longer arises. It is therefore convenient in applications to use, in lieu of the random process, $\zeta(t)$, its largest value during the lifetime of the structure, denoted by $X(n)$. By substituting the random variable, $X(n)$, for the random process, $\zeta(t)$, the treatment of the reliability problem is simplified considerably. The largest lifetime value, $\mathrm{X}(\mathrm{n})$, can be characterized probabilistically as follows:

$$
\mathrm{F}_{\mathrm{X}}(\mathrm{n})(\mathrm{x})=\left[\mathrm{F}_{\mathrm{X}}(1)(\mathrm{x})\right]^{\mathrm{n}}
$$

a For brevity, nominal failure probabilities are henceforth referred to simply as failure probabilities. 
where $x^{(1)}=$ extreme value of $\zeta(t)$ during a time interval $t_{1}=T / n, T=$ lifetime of structure, $n$ = integer and $F_{X}(n)$ = cumulative distribution function of $X(n)$. The cumulative distribution function of $\mathrm{X}^{(1)}, \mathrm{F}_{\mathrm{X}}(1)$, is referred to as the parent distribution of $\mathrm{X}(n)$. Equation 2 holds if successive values of $X(1)$ are identically distributed and statistically independent. An application of equation 2 is presented in the following example.

Example. Let $\mathrm{X}^{(1)} \equiv \mathrm{U}_{\mathrm{a}}$ denote the largest yearly wind speed at a given location. Then $X(n) \equiv U$ denotes the largest wind speed occurring at that location during an n-year period (equal to the lifetime of the structure). It is assumed that the largest yearly wind speed, $U_{a}$ has an Extreme Value Type I distribution, i.e.,

$F_{U_{a}}\left(u_{a}\right)=\exp \left[-\exp \left(-\frac{u_{a}-\mu}{\sigma}\right)\right]$

It can be shown that

$$
\begin{aligned}
& \mu \simeq \bar{U}_{a}-0.45 \sigma_{\mathrm{U}} \\
& \sigma \simeq 0.78 \sigma_{\mathrm{U}}
\end{aligned}
$$

where $\bar{U}_{a}$ and $\sigma_{U}=$ sample mean and sample standard deviation of the largest annual wind speed data, $U_{a}$. From Eqs. 2 through 5 it follows that the probability distribution of the largest lifetime wind speed, $U$, is:

$$
F_{U}(u)=\exp \left[-\exp \left(-\frac{u-\mu_{n}}{\sigma_{n}}\right)\right]
$$

where

$$
\begin{aligned}
& \mu_{\mathrm{n}} \simeq \overline{\mathrm{U}}-0.45 \sigma_{\mathrm{U}} \\
& \sigma_{\mathrm{n}} \simeq 0.78 \sigma_{\mathrm{U}} \\
& \overline{\mathrm{U}}=\overline{\mathrm{U}}_{\mathrm{a}}+0.78 \sigma_{\mathrm{U}} \ln \mathrm{n} \\
& \sigma_{\mathrm{U}}=\sigma_{\mathrm{U}}
\end{aligned}
$$

and $\mathrm{n}=$ lifetime of structure in years. 
Finally, we consider the case where the structure is acted upon by two randomly time-dependent loads with the following properties: (1) their extreme values have negligible probability of simultaneous occurrence, (2) their most unfavorable combination occurs when one of the loads reaches its largest lifetime value, while the other has an "ordinary" (also termed "arbitrary-point-in time"), rather than an extreme, valuea. Since the "arbitrary-point-in-time" loading can be modeled by an appropriately chosen time-independent probability distribution [13], the reliability problem can in this case also be reduced to one involving only random variables.

\section{Failure and Safe Regions, Failure Boundary}

Consider a structure or member subjected to a load Q, and let the value of the loading that induces a certain limit state in the structure (e.g•, the yield stress) be denoted by $R$. It is assumed that both $Q$ and $R$ are random variables. The space defined by these variables is referred to as the load space. By definition, failure occurs for any pair of values, $Q, R$, satisfying the relation

$$
R-Q<0
$$

Equation 10 defines the failure region in the load space. The survival region, or safe region, is defined by the relation

$$
R-Q>0
$$

The failure boundary, which separates the failure and safe regions, is defined by the equation

$$
R-Q=0
$$

Relations similar to equations 10,11 , and 12 can be written in the load effect space, defined by the variables $Q_{e}, R_{e}$, where $Q_{e}$ is the effect, or state, induced in the structure by the load Q (e.g., a state of stress or deformation), and $R_{e}$ is the corresponding capacity (e.g., the yield stress or a specified deformation). The equation of the failure boundary in the load effect space is

$$
R_{e}-Q_{e}=0
$$

In general, $Q$ and $R$ are functions of random variables $X_{1}, X_{2}, \ldots X_{n}\left(e_{.}\right.$. , aerodynamic coefficients, terrain roughness, cross-sectional area, modulus of

a For example, it may be assumed that these properties characterize the wind load and the live load acting on members of high-rise building frames. 
elasticity, breaking strength)a, i.e.,

$$
\begin{aligned}
& 0=Q\left(x_{1}, x_{2}, \ldots x_{n}\right) \\
& R=R\left(x_{1}, x_{2}, \ldots x_{n}\right)
\end{aligned}
$$

Substitution of equations 14 and 15 into equations 10,11 , and 12 yields the mapping of the failure region, safe region, and failure boundary onto the space of the variables $x_{1}, x_{2}, \ldots, x_{n}$. The equation of the failure boundary thus can be written as

$$
g\left(x_{1}, x_{2}, \ldots, x_{n}\right)=0
$$

The well-behaved nature of structural mechanics relations generally ensures that equation 13 is the mapping of equation 12 onto the load effect space. Equation 16 is thus the mapping onto the space $x_{1}, x_{2}, \ldots, x_{n}$ not only of equation 12, but of equation 13 as well. Therefore, once it is made clear-at the outset that the problem is formulated in the load, or in the load effect, space, it is permissible to refer generically to $Q$ and $Q_{e}$ as "loads" and to $R$ and $R_{e}$ as "resistances", and to omit the index "e" in equation 13.

The important case is noted where relations between loads and/or resistances and more fundamental variables of the problem, $x_{1}, x_{2}, \ldots x_{n}$, can only be obtained numerically. In that case, equation 16 cannot, in general, be written in closed form.

It is useful in various applications to map the failure region, the safe region, and the failure boundary onto the space of the variables $Y_{1}, Y_{2}, \ldots, Y_{Y}$, defined by transformations

$$
\mathrm{Y}_{i}=\mathrm{Y}_{1}\left(\mathrm{X}_{1}, \mathrm{X}_{2}, \ldots, \mathrm{X}_{\mathrm{n}}\right)(\mathrm{i}=1,2, \ldots, \mathrm{r})
$$

For example, if in equation $16 \mathrm{X}_{1}=\rho$, and $\mathrm{X}_{2}=\mathrm{U}$, where $\rho=$ air density and $U=$ wind speed, a variable representing the dynamic pressure may be defined by the transformation $\mathrm{Y}_{1}=1 / 2 \rho \mathrm{U}^{2}$, and equation 16 may be mapped onto the space of the variables $\hat{Y}_{1}, X_{3}, X_{4}, \ldots, X_{n}$. Another example is the frequently used set of transformations

$$
\begin{aligned}
& Y_{1}=\operatorname{lnR} \\
& Y_{2}=\ln Q
\end{aligned}
$$

a These are sometimes referred to as basic variables. We will use here simply the term "variables", since what constitutes a basic variable is in many instances a matter of convention. For example, the hourly wind speed at 10 m above ground in open terrain, which is regarded in most applications as a basic variable, depends in turn upon various random storm characterist1cs, such as the difference between atmospheric pressures at the center and the periphery of the storm, the radius of maximum storm winds, and so forth. 
It follows immediately from equations 12, 18, and 19 that the mapping of the failure boundary onto the space $\mathrm{Y}_{1}, \mathrm{Y}_{2}$, is

$$
\mathrm{Y}_{1}-\mathrm{Y}_{2}=0
$$

or

$$
\ln R-\ln Q=0
$$

The failure boundary is a point, a curve, a surface, or a hypersurface according to whether the problems at hand is formulated in a space of one, two, three, or more than three random variables.

\section{General Expression for Estimation of Failure Probability}

Let the failure region in the space of reduced variables ${ }^{a} x_{1_{r}}, x_{2} \ldots . x_{n_{r}}$, be denoted by $\Omega$. The probability of failure $P_{f}$, can be written as:

$$
P_{f}=\int_{\Omega}{ }_{x_{1_{r}}}, x_{2_{r}}, \ldots x_{n_{r}}\left(x_{1_{r}}, x_{2}, \ldots x_{n_{r}}\right) d x_{1_{r}} d x_{2} \ldots d \ldots x_{n_{r}}
$$

where the integrand is the joint probability density function of the reduced variables.

In most cases the estimation of failure probabilities by equation 22 is computationally unwieldy, if not prohibitive, and the use of alternative methods is attempted instead. Various such methods, whose applicability depends upon the characteristics of the problem at hand, are described following the introduction in the next section of the useful notion of safety index.

\section{Safety Indices}

The safety index is a statistic which, under certain conditions that will be illustrated subsequently, can provide a simple and convenient means of assessing structural reliability.

a The reduced (or standardized variable, $x_{r}$, corresponding to a variable, $x$, is defined as

$\mathrm{x}_{\mathrm{r}}=\frac{\mathrm{x}-\overline{\mathrm{X}}}{\sigma_{\mathrm{x}}}$

where $\bar{X}$ and $\sigma_{x}$ are the mean and standard deviation of $x$, respectively.

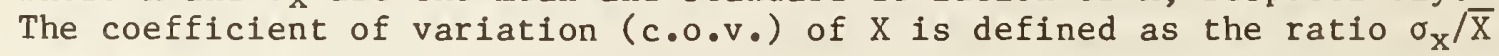
and is denoted by $V_{X}$. 
We consider a failure boundary in the space of a given set of variables, and denote by $S$ its mapping in the space of the corresponding reduced variables.

The safety index, $\beta$, is defined as the shortest distance in this space between the origin and the boundary $S[14]^{a}$. The point on the boundary $S$ that is closest to the origin, as well as its mapping in the space of the original variables, is referred to as the checking point. For any given structural problem, the numerical value of the safety index depends upon the set of variables in which the problem is formulated. The examples that follow illustrate the meaning of the safety index and the dependence of its numerical value upon the set of variables being used.

Example 1. It is assumed that the only randon variable of the problem is the load (effect) Q. The resistance--a deterministic ouantity--is denoted by $R$. The mapping of the failure boundary

$$
0-\bar{R}=0
$$

onto the space of the reduced variable $q_{r}=(Q-\bar{Q}) / \sigma_{Q}(i \cdot e$. , onto the axis $O_{q}-$ see figure 1$)$ is a point, $q_{r}$, whose distance from the origin 0 is $B=(R-Q) / \sigma_{Q}$. The safety index represents in this case the difference between the values $R$ and $Q$ measured in terms of standard deviations, $\sigma Q$. It is clear that the larger the safety index $B$ (i.e., the larger the difference $R-Q$ for any given $\sigma_{Q}$, or the smaller $\sigma_{Q}$ for any given difference $R-Q$ ), the smaller the probability that $Q \geq R$.

Example 2. Consider the failure boundary in the load space (ecuation 10), and assume that both $R$ and $Q$ are random variables. The mapping of equation 12 onto the space of the reduced variables $q_{r}=(Q-Q) / \sigma_{Q}$ and $r_{r}=(R-R) / \sigma_{Q}$ is the line [13]

$$
\sigma_{\mathrm{OQ} r}+\bar{Q}-\sigma_{R} r_{r}-R=\overline{0}
$$

(figure 2). The distance between the origin and this line is

$$
B=\frac{\bar{R}-\bar{Q}}{\left(\sigma_{R}{ }^{2}+\sigma_{Q}{ }^{2}\right)^{1 / 2}}
$$

a This definition is applicable to statistically independent variables. If the variables of the problem are correlated, they can be transformed by a linear operator into a set of independent variables [14]. Note that an alternative, generalized safety index was proposed in reference 15, whose performance is superior in situations where the fallure boundarles are nonlinear (see also Chapter 9 of reference 16 ). 
This definition of the safety index was suggested in [20].

Example 3. Instead of operating in the load space $R$, $Q$, we consider equation 20, $\mathrm{i} . e$. , the failure boundary in the space $\mathrm{Y}_{1}, \mathrm{Y}_{2}$, defined by equations 18 and 19. Following exactly the same steps as in the preceding example, but applying them to the variables $\mathrm{Y}_{1}$ and $\mathrm{Y}_{2}$, the safety index is in this case

$$
\beta=\frac{\bar{Y}_{1}-\bar{Y}_{2}}{\left(\sigma_{Y_{1}}{ }^{2}+\sigma_{Y_{2}}{ }^{2}\right)^{1 / 2}}
$$

Expansion in a Taylor series yields

$$
\mathrm{Y}_{1}=\ln \overline{\mathrm{R}}+(\mathrm{R}-\overline{\mathrm{R}}) \frac{1}{\overline{\mathrm{R}}}-\frac{1}{2}(\mathrm{R}-\overline{\mathrm{R}})^{2} \frac{1}{\overline{\mathrm{R}}^{2}}+\ldots
$$

and a similar expression for $\mathrm{Y}_{2}$. It then follows that if $\mathrm{R}$ and $\mathrm{Q}$ are uncorrelated,

$$
B \simeq \frac{\ln \bar{R}-\frac{1}{2} V_{R}^{2}-\left(\ln \bar{Q}-\frac{1}{2} V_{Q}^{2}\right)}{\left(V_{R}^{2}+V_{Q}^{2}\right)^{1 / 2}}
$$

where $V_{R}$ and $V_{Q}$ denote the coefficient of variation of $R$ and $Q$, respectively. If higher order terms in the numerator of equation 28 are neglected, which is reasonable provided that $V_{R}$ and $V_{Q}$ are less than 0.3 , say,

$$
B \simeq \frac{\ln (\bar{R} / \bar{Q})}{\left(V_{R}^{2}+v_{Q}^{2}\right)^{1 / 2}}
$$

This definition of the safety index was used, e.g., in [22].

Example 4. Consider a linearly elastic member whose stresses, O, can be written as

$$
0=\mathrm{aU}^{2}
$$

where $a=$ deterministic influence coefficient and $U=$ wind speed. We assume that $\mathrm{a}=0.00267 \mathrm{ksi} /(\mathrm{mph})^{2}$; the mean and standard deviation of the largest annual wind speed are $U_{a}=43.73 \mathrm{mph}$ and $\sigma_{U}=8.61 \mathrm{mph}$; the mean and standard deviation of the resistance are $R=35.3 \mathrm{ksi}$ and $\sigma_{R}=3.39 \mathrm{ksi}$; and that the lifetime of the member is $\mathrm{n}=50$ years. From equations 8 and 9 , it follows that the mean and standard deviation of the 
largest lifetime wind speed are $U=70 \mathrm{mph}, \sigma_{U}=8.61 \mathrm{mph}$. An expansion of equation 30 in a Taylor series about the mean, $U$, yields

$$
\bar{Q}=\mathrm{aU}^{2}\left(1+\mathrm{V}_{\mathrm{U}}^{2}\right)
$$

and

$$
\mathrm{V}_{\mathrm{Q}} \simeq 2 \mathrm{~V}_{\mathrm{U}}
$$

i.e., $\overline{0} \simeq 13.3 \mathrm{ksi}$ and $\sigma_{Q} \simeq 3.27 \mathrm{ksi}$. The equation of the failure surface in the space of the variables $U, R$ is

$$
a U^{2}-R=0
$$

and 1 ts mapping in the space of the reduced variables $u_{r}, r_{r}$ is

$$
\left(u_{r}+\frac{\bar{U}}{\sigma_{U}}\right)^{2}=\frac{\sigma_{R}}{a \sigma_{U}^{2}}\left(r_{r}+\frac{\bar{R}}{\sigma_{R}}\right)
$$

The value of the safety $j_{*}$ ndex is $\beta=4.31$ (figure 3 ). The coordinates of the checking point are $\mathrm{r}_{\mathrm{r}}^{*}=-2.51, \mathrm{u}_{\mathrm{r}}^{*}=3.50$, to which there correspond in the $U, R$ space the coordinates $U^{*}=100.14 \mathrm{mph}, \mathrm{R}^{*}=26.76 \mathrm{ksi}$. It can be verified that the values of the safety index corresponding to the variables $Q, R$ (equation 25) and $2 n Q$, $\ell n R$ (equation 29) are $B \simeq 4.66$ and $B \simeq 3.69$, respectively.

Note that the mean and standard deviation of the largest lifetime wind speed or of the largest lifetime load, which are needed for the calculation of the safety index, cannot be estimated directly from measured data, but must be obtained from the probability distribution of the lifetime extreme. This distribution is estimated from the parent distribution that best fits the measured annual extreme data. Knowledge of, or an assumption concerning, the parent probability distribution is required for the estimation of the safety index in all cases involving a random variable that represents a lifetime extreme.

Safety Indices and Failure Probabilities: The Case of Normal Variables Consider the space of the variables $Q$ and $R$, and assume that both variables are normally distributed. Note that the failure boundary (equation 12) is linear. Since the variate $R-Q$ is normally distributed, the probability of failure can be written as

$$
\begin{aligned}
P_{f} & =F(R-Q<0) \\
& =\frac{1}{\sqrt{2 \pi} \sigma_{R}-Q} \int_{-\infty}^{0} \exp \left[-\frac{1}{2}\left(\frac{x-(\overline{R-Q})}{\sigma_{R}-Q}\right)^{2}\right] d x \\
& =1-\Phi\left(\frac{\bar{R}-\bar{O}}{\sqrt{\sigma_{R}^{2}+\sigma_{Q}^{2}}}\right)
\end{aligned}
$$


where $\Phi$ = standardized normal cumulative distribution function, and the quantity between parentheses is the safety index, $B$, corresponding to the space of the variables $R$, Q (equation 25).

More generally, it can similarly be shown that the relationship

$$
P_{f}=1-\Phi(\beta)
$$

is valid if all the independent variables, $\mathrm{X}_{1}, \mathrm{X}_{2}, \ldots \mathrm{X}_{\mathrm{n}}$ are normally distributed, the failure boundary (equation 16) is a linear function, and $\beta$ is the safety index in the space of the reduced variables $x_{1}, x_{2}, \ldots, x_{n_{r}}$.

Equation 36, of which equation 35 is a particular case, can be used even if the variables $x_{1}, x_{2}, \ldots, x_{n}$ are not normally distributed and the failure boundary $g\left(x_{1}, X_{2}, \ldots, X_{n}\right)=0$ is nonlinear, provided that a transformation of variables $Y_{i}=f_{i}\left(X_{i}\right)(i=1,2, \ldots, n)$ can be found such that $Y_{i}$ are normally distributed and the failure boundary in the space $Y_{1}, Y_{2}, \ldots, Y_{n}$ is linear. For example, assume that $R$ and $Q$ have lognormal distributions. Then $Y_{1}=\ell n Q$ and $\mathrm{Y}_{2}=$ \&nR are normally distributed, and the equation of the failure boundary is $\mathrm{Y}_{1}-\mathrm{Y}_{2}=0$ (equation 20). Applying equation 36 to the variables $\mathrm{Y}_{1}$ and $\mathrm{Y}_{2}$,

$$
\begin{aligned}
P_{f} & =1-\Phi\left(\frac{\overline{\ell n R}-\overline{\ell n Q}}{\sqrt{\sigma_{\ell n R}{ }^{2}+\sigma_{\ell n Q}{ }^{2}}}\right) \\
& \simeq 1-\Phi\left(\frac{\ln (\bar{R} / \bar{Q})}{\sqrt{v_{R}^{2}+v_{Q}^{2}}}\right)
\end{aligned}
$$

The quantities between parentheses in equation 37 may be recognized, respectively, as the exact and approximate expression for the safety index, $\beta$, corresponding to the space of the variables $\operatorname{lnR}$, $\ell$ nQ (equations 26 and 29).

Safety Indices and Failure Probabilities: The Case of Non-normal Variables

If the variables $x_{1}, x_{2}, \ldots x_{n}$, are non-normal, or functions thereof are noninear, equation 36 is not applicable. The fact that equation 36 does not hold means that members having the same safety index will, in general, have different failure probabilities. To illustrate the relationship between safety index and failure probability we consider the four members for which the means and standard deviations of the load and resistance are listed in table 1. Members I and II have the same value of $\beta$ in the space of the reduced variables $y_{1}$, $y_{2}$ (corresponding to equations 18 and 19); their failure boundaries in that space are shown in figure 4. Members II, III, and IV have the same value of $\beta$ in the space of the reduced variables $r_{r}, q_{r}$, representing the resistance and the load, respectively. The probabilities of failure of the four members based on the assumption that all the variables are normal are shown in column 8, Table 1. Those corresponding to the assumption that all the variables are 


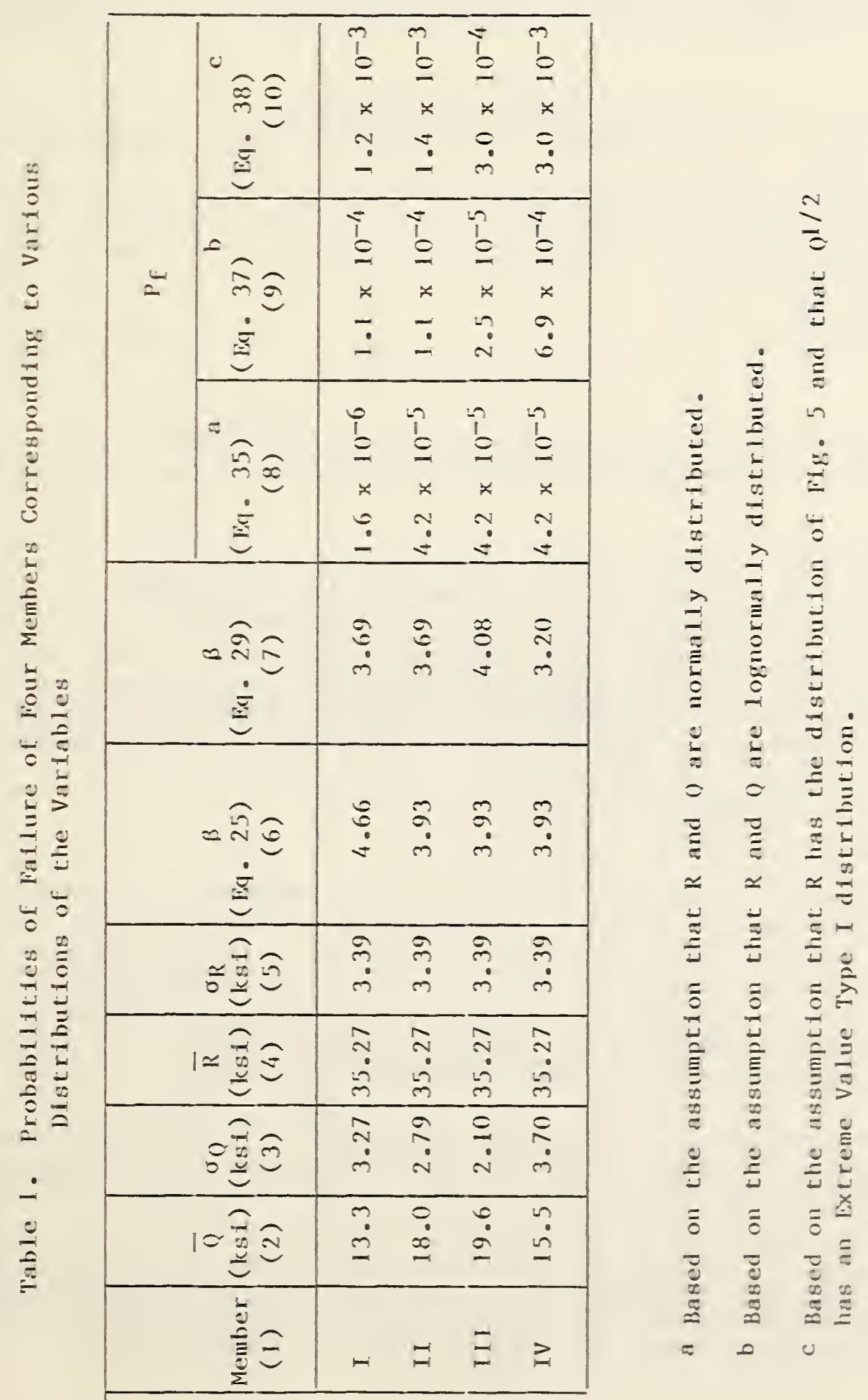


lognormally distributed are listed in column 9. Column 10 shows the failure probabilities based on the assumptions that (a) the load is given by equation 30, (b) the distribution of the wind speed is Extreme Value Type I, and (c) the reduced variable representing the resistance has the probability density function $f_{\rho}\left(r_{r}\right)$, shown in figure $5^{a}$. (From equations 6 and 22 it follows that the failure probability based on these assumptions has the expression

$$
\begin{aligned}
& \mathrm{P}_{\mathrm{f}} \simeq \frac{1}{0.78} \int_{\frac{-\bar{U}}{\sigma_{U}}}^{\infty} \exp \left\{-\exp \left[-\frac{u_{r}+0.45}{0.78}\right]-\frac{u_{r}+0.45}{0.78}\right\} d u_{r} \\
& \times \quad \int_{-\frac{\bar{R}}{\sigma_{R}}}^{\frac{a \sigma_{U}{ }^{2}}{\sigma_{R}}\left(u_{r}+\frac{\bar{U}}{\sigma_{U}}\right)^{2}-\frac{\bar{R}}{\sigma_{R}}}
\end{aligned}
$$

in which $U$ and $V_{U}$ are related to $Q$ and $V_{Q}$ as shown by equations 31 and 32. ) The probabilities of column 10 were obtained by evaluating the integrals of equation 38 .

It is seen from table 1 that to equal values of the safety index, $\beta$, calculated by equation 25 (which is based on the assumption that the probability distributions of $Q$ and $R$ are normal), there correspond failure probabilities calculated by quadrature (column 10) that vary by as much as one order of magnitude (members II, III, and IV). On the other hand, results of numerical studies reported in reference 17 showed that, for values of $\beta$ comparable to these of column 9, equation 38 can be fitted to within a factor smaller than two by the curve

$$
\mathrm{P}_{\mathrm{f}} \simeq \exp \left[-\left(\frac{\beta+0.45}{0.835}\right)^{1 / 0.85}\right]
$$

where $\beta$ is calculated by equation 29; that is, the probability of failure, $P_{f}$, is, at least approximately, determined uniquely by the safety index $\beta$ calculated by equation 29, regardless of the relative values of $Q, V_{Q}, R$, and $V_{R}$. This interesting conclusion - which, as was just pointed out, does not hold for the safety index, $\beta$, calculated by equation 25 - is explained by the approximate similarity between the shapes of the lognormal distribution on the one hand, and the distributions used in equation 38 on the other hand.

Note, however, that while this conclusion is valid in the particular case just examined, it does not necessarily hold in other situations. For example, it

a This shape corresponds approximately to published data on the yield stress of A33 steel, for which the nominal value, the mean value, and the coefficient of variation are $\mathrm{F}_{\mathrm{y}}=33 \mathrm{ksi}, \overline{\mathrm{R}} \simeq 1.07 \mathrm{~F}_{\mathrm{y}}$, and $\mathrm{V}_{\mathrm{R}} \simeq 0.096[17 ; 18$, p. 237]. 
is possible that two members, one subjected to gravity loads and the other to wind or wave loads, will have widely different failure probabilities even if their safety indices calculated by equation 29 are nearly equal. In this case, or in similar cases, a comparative reliability analysis would require the estimation of the failure probability by equation 22 or by alternative, approximate methods. A few such methods are briefly described in the following section.

\section{Approximate Methods for Estimating Failure Probabilities}

We first describe the method referred to as normalization at the checking point [19]. The principle of the method is to transform the variables, $X_{1}$, into a set of approximately equivalent normal variables, $x_{i}^{n}$, having the following property:

$$
\begin{aligned}
& \mathrm{P}_{\mathrm{X}_{1}}\left(\mathrm{X}_{1}^{*}\right)=\mathrm{f}\left(\mathrm{X}_{1}^{\mathrm{n}^{*}}\right) \\
& =\frac{1}{\sigma_{X_{i}^{n}}^{n}} \phi\left(x_{1}^{n *}\right) \\
& \mathrm{P}_{\mathrm{X}_{1}}\left(\mathrm{X}_{i}^{*}\right)=\mathrm{F}\left(\mathrm{X}_{i}^{\mathrm{n}_{*}}\right) \\
& =\Phi\left(\mathrm{x}_{\mathrm{i}}^{\mathrm{n}^{*}}\right)
\end{aligned}
$$

where $1=1,2, \ldots, m$, the asterisk denotes the checking point, $\mathrm{p}_{\mathrm{X}}$ and $\mathrm{P}_{\mathrm{X}}$ are the probability density function and cumulative distribution function of $\mathrm{X}_{1}$, respectively, $f$ and $\phi$ are the normal and standardized normal probability density function, respectively, $F$ and $\Phi$ are the normal and standardized normal cumulative distribution function, respectively, $x_{i_{r}}^{n}$ is the reduced variable corresponding to $\mathrm{X}_{1}^{\mathrm{n}}$, and $\sigma_{\mathrm{X}^{\mathrm{n}}}$ is the standard deviation of $\mathrm{X}_{1}^{\mathrm{n}}$. From equations 40 and 41 it follows that

$$
\begin{aligned}
& \sigma_{X_{i}^{n}}=\frac{\phi\left(\Phi^{-1}\left[P\left(X_{i}^{*}\right)\right]\right.}{P_{X_{i}}\left(X_{i}^{*}\right)} \\
& X_{i}^{n}=X_{i}^{*}-\Phi^{-1}\left[P_{X_{i}}\left(X_{i}^{*}\right)\right] \sigma_{X_{i}^{n}}^{n}
\end{aligned}
$$

where the bar denotes mean value. Once $\overline{X_{1}^{n}}$ and $\sigma_{X_{1}^{n}}$ are obtained from equations 42 and 43 , the problem can be restated in the space of the reduced variables, $x_{i_{r}}^{n}$. The safety index, $\beta$, is the distance in this space between the origin and the fallure boundary. A computer program for calculating this 
distance, based on an algorithm proposed in reference 19, is presented in reference 13. Following the calculation of $\beta$, the probability of failure is estimated by equation 36 .

The procedure just described is approximate because equation 36 does not hold if the failure boundary is nonlinear.

A method for reducing the errors due to the nonlinearity of the failure boundary was proposed in reference 21. Following normalization at the checking point, relations similar in principle to equation 36 are used that correspond to the case where the failure boundary is a quadric, rather than a (hyper) plane. The failure probability depends upon the safety index corresponding to the space of the coordinates $\mathrm{X}_{i}^{\mathrm{n}}$ and upon the characteristics of the quadric. The latter are determined from the condition that the quadric approximates the nonlinear failure boundary as closely as possible at the checking point.

An alternative procedure was proposed in reference 22, in which the failure boundary in the space of the original, non-normal variables is written in the form

$$
g\left(x_{1}, x_{2}, \ldots, x_{n}\right)=\sum_{i=1}^{n} Y_{i}\left(x_{1}\right)
$$

The functions $Y_{i}\left(X_{1}\right)$ can be determined by approximate methods briefly described in reference 17. Equation 44 is in effect a linearization of the failure boundary in the space of the variables $Y_{i}$. The probability distributions of the variables $Y_{i}$ are estimated from the distributions of $X_{i}$. An approximate method for carrying out such estimates, which usually involves elementary algebraic operations, is described in references 23 and 24. The probability distributions of $Y_{1}$ can also be estimated by Monte Carlo simulations. Once these distributions are known, the method of normalization at the checking point is applied to the variables $Y_{1}$. The safety index, $\beta$, is then calculated in the space of the reduced equivalent normal variables, and equation 36 can be applied to obtain the failure probability.

\section{Safety Factors}

Consider a structure characterized by a set of variables with means and standard deviations $x_{i}$ and $\sigma_{X_{i}}$, and checking points with coordinates $x_{i}^{*}$ and $x_{i}^{*}$ ( ${ }^{*}=$ $1,2, \ldots \mathrm{n})$ in the space of the original and the reduced variables, respectively. By definition:

$$
x_{i}^{*}=\bar{x}_{i}+\sigma_{x_{i}} x_{i}^{*}
$$


Equation 47 can be written as

$$
x_{i}^{*}=\gamma_{X_{i}} \bar{x}_{i}
$$

where

$$
r_{x_{i}}=1+v_{X_{i}} x_{i}^{*}
$$

The quantity $\sqrt{x}_{i}$ is termed the partial safety factor applicable to the mean of the variable $\mathrm{X}_{1}$.

In design applications the means, $X_{i}$, are seldom used, and nominal design values, such as the 100-year wave, the allowable steel stress, $F_{a}$, or the nominal yield stress, $F_{y}$, are employed instead. Let these nominal values be denoted by $\mathbb{X}_{i}$. Equation 46 can be rewritten as [13]

$$
x_{i}^{*}=\tilde{r}_{X_{i}} \tilde{x}_{i} \quad(i=1,2, \ldots, n)
$$

where

$$
\gamma \tilde{X}_{i}=\frac{\bar{X}_{i}}{\tilde{X}_{i}} \bar{X}_{i}
$$

The factor $\gamma_{X_{i}}$ is the partial safety factor applicable to the nominal design value of the variable $x_{i}$.

In the particular case in which the variables of concern are the load, 0 , and the resistance, $R$, the partial safety factors are referred to as the load and resistance factor. For the resistance factor the notation $\phi_{\bar{R}}$ or $\hat{\phi}_{R}$ is used in lieu of $Y_{\bar{R}}$ or $\gamma_{R_{R}}$.

From the definition of the partial safety factor (equation 47) and the definftion of the checking point in the space of the reduced variables corresponding to $Y_{1}=2 n R$ and $Y_{2}=2 n Q$, it follows that if higher order terms (see equation 27) are neglected

$$
\begin{aligned}
& \hat{\rho}_{R}^{-} \simeq \exp \left(-\alpha_{R} \beta V_{R}\right) \\
& \gamma_{Q}^{-} \simeq \exp \left(\alpha_{Q} \beta V_{Q}\right) \\
& \alpha_{R}=\cos \left[\tan ^{-1}\left(V_{Q} / V_{R}\right)\right] \\
& \alpha_{Q}=\sin \left[\tan ^{-1}\left(V_{Q} / V_{R}\right)\right]
\end{aligned}
$$


where $\beta=$ safety index given by equation 29 .

Care must be exercised in using simplified approximate expressions for partial safety factors. To show this, we consider below an application of the following expression for the load factor, $\gamma_{\bar{Q}}$, proposed in reference 23 as an approximation to equation 51 for members subjected to wind loads:

$$
\bar{\gamma}_{\mathrm{Q}}=1+0.55 \beta \mathrm{V}_{\mathrm{Q}}
$$

where $\beta$ is calculated by equation 29.

Example. For members I and II of table 1, it would follow from equation 54 that $\gamma_{Q_{I}}=1.50$ and $\gamma_{Q_{I I}}=1.31$, respectively. However, if equation 51 is used, $\gamma_{Q_{I}}=2.32$ and $\gamma_{Q_{I I}}=1.63$. It is concluded that equation 4 may result in misleading estimates of the load factor $\gamma_{Q^{-}}$.

Equations 50 and 51 show that load and resistance factors depend not only on the safety index, $\beta$, but on the coefficients of variation $V_{Q}, V_{R}$ as well. For this reason, to members having the same safety index $\beta$ there can correspond widely different sets of load and resistance factors as calculated by equations 50 and 51 . This is illustrated in the following example.

Example. Members I and II of table 1 have the same safety index calculated by equation 29 (as well as approximately the same failure probabilities -- see column 10 of table 1$)$. The values of $V_{R}$ for the two members are also the same; however the respective values of $V_{Q}$ differ (table 1). It can be verified that, owing to this difference, the load and resistance factors for the two members (given by equations 50 through 53) are $\phi_{\mathrm{R}_{\mathrm{I}}}^{-} \simeq 0.88$ versus $\phi_{\mathrm{R}_{\mathrm{II}}}^{-} \simeq 0.83$ and, as indicated earlier, $\gamma_{Q_{I}}=2.32$ versus $\gamma_{Q_{I I}}^{-}=1.63$

Conversely, the use in the design of various members of the same set of load and resistance factors does not necessarily ensure that those members will have the same probabilities of failure. This creates difficulties in the development of risk-consistent load and resistance factors for codified design. These difficulties, and proposed approaches for dealing with them, are discussed in reference 13 and 15. Problems related to codes of practice are also discussed in reference 24 . 


\section{SUMMARY AND CONCLUSIONS}

A review was presented of fundamental topics in structural reliability that are potentially applicable to ocean engineering problems. As mentioned in the report, although a number of studies concerned with structural systems have been reported (e.g., references 2 to 7), the practical usefulness of such studies remains limited, particularly as far as ocean engineering applications are concerned. The present report is concerned with applications to individual members.

Some of the potential advantages of reliability methods in the context of offshore platform analysis and design have been outlined in reference 25 . In the present report such methods have been subjected to an independent critical review aimed at highlighting possible difficulties and pitfalls in their application. Principal conclusions of the review are:

1. Uncertainties with respect to structural behavior and to probabilistic characterizations of relevant parameters can render difficult, if not impossible, meaningful comparisons between estimated safety levels of members belonging to different types of structure or to structures subjected to different types of load. These difficulties are compounded by the fallure of most current reliability methods to account adequately for the complexities of systems reliability behavior, particularly in cases involving time dependent loads such as wind or waves.

2. Reliability methods based on the use of safety indices cannot be applied in cases involving a random variable that represents a lifetime extreme unless an explicit assumption is made with regard to the parent probability distribution of that variable.

3. Reliability methods based on the use of safety indices or load and resistance factors can in certain instances provide useful comparisons between the safety levels of certain types of members. This is the case only if it can be determined that the relation between the safety index and the failure probability for those members is independent of, or weakly dependent upon, the relative values of the mean and coefficients of variation of the resistances and of the loads.

4. Simplified approximate expressions for partial safety factors should be used with caution, and their range of applicability should be carefully checked against the "exact" expressions from which they are derived.

The writers believe that the observations presented in this report can be helpful in ensuring that reliability analyses conducted for of fshore structures can be used prudently and confidently by both practitioners and regulatory bodies. 


\section{REFERENCES}

1. Safety Goals for Nuclear Power Plant Operation. NUREG-0880, Revision 1, U.S. Nuclear Regulation Commission Office of Policy Evaluation, Washington, D.C., May 1893.

2. P. Thoft - Christensen, and M. J. Baker, Structural Reliability Theory and Applications, Springer-Verlag, Berlin, 1982 .

3. F. Moses, Utilization of a Reliability-Bases API RP2A Format on Platform Design, API PRAC Project 81-22, American Petroleum Institute, Dallas, TX, Nov. 1982.

4. R. M. Bennett and A. H.-S. Ang, Investigation of Methods for Structural System Reliability, UILU-ENG-83-2014, Dept. of Civil Engineering, University of Illinois, Urbana, Illinois, Sept. 1983

5. C. A. Corne11, R. Rackwitz, Y. Guénard, and R. Bea, Reliabiltiy Evaluation of Tension Leg Platforms, in Proceedings of the 4th ASCE Specialty Conference on Probablistic Mechanics and Structural Reliability, Y.-K. Wen, ed., January 11-13, 1984, Berkeley, Calif.

6. F. Moses, "Reliability of Structural Systems," Journal of the Structural Division," ASCE, Sept. 1974, pp. 1813-1820.

7. E. Vanmarcke and D. Angelides, "Risk Assessment for Offshore Structures: A Review," Journal of Structural Engineering, Feb. 1983, pp. 555-571.

8. American National Standard Minimum Design Loads for Buildings and Other Structures, ANSI A58.1-1982, American National Standards Institute, New York, N.Y., 1982.

9. T. V. Galambos, et al., "Probability Based Load Criteria: Assessment of Current Design Practice," Journal of the Structural Division, ASCE, May 1982, pp. 959-977.

10. R. Fleming, Wind Stresses, Engineering News, New York, 1915 (Reprints from Engineering News, 1915).

11. Y. K. Wen, "Statistical Combination of Extreme Loads," Journal of the Structural Division, ASCE, May 1977, pp. 1079-1095.

12. R. D. Larrabee, and C. A. Cornell, "Combination of Various Load Processes," Journal of the Structural Division, ASCE, January 1981, pp. 223-239.

13. B. Ellingwood et al., Development of a Probability Based Load Criterion for American National Standard A58, NBS Special Publication 577, National Bureau of Standards, Washington, D.C., June 1980. 
14. A. M. Hasofer, and N. C. Lind, "Exact and Invariant Second-Moment Code Format," Journal of the Engineering Mechanics Division, ASCE, February 1978, pp. 829-844.

15. 0. Ditlevsen, "Generalized Second Moment Reliability Index," Journal of Structural Mechanics, Vol. 7 (1979) pp. 435-451.

16. 0. Ditlevsen, Uncertainty Modeling, McGraw-Hill International Book Company, New York, N.Y., 1981 .

17. E. Simiu, and J. R. Shaver, "Wind Loading and Reliability-Based Design," in Wind Engineering, Proceedings of the Fifth International Conference, Fort Collins, Colorado, USA, July 1979, Vol. 2, Pergamon Press; OxfordNew York, 1980.

18. W. McGuire, Steel Structures, Prentice Hall, Inc., Englewood Cliffs, N.J., 1968.

19. R. Rackwitz, and B. Fiessler, Non-normal Distributions in Structural Reliability, SFB 96, Technical University of Munich, Ber. zur Sicherheitstheorie der Bauwerke, No. 29, 1978, pp. 1-22.

20. C. A. Corne11, "A Probability-Based Structural Code," ACI Journal, Dec. 1969.

21. B. Fiessler, H.-J Newmann, and R. Rackwitz, "Quadratic Limit States in Structural Reliability," Journal of the Engineering Mechanics Division, ASCE, August 1979, pp. 661-676.

22. T. V. Galambos, and M. K. Ravindra, Tentative Load and Resistance Factor Design Criteria for Steel Buildings, Research Report No. 18, Civil Engineering Department, Washington University, St. Louis, MO, Sept. 1973.

23. M. K. Ravindra, C. A. Cornell, and T. V. Galambos, "Wind and Snow Load Factors for Use in LRFD," Journal of the Stuctural Division, ASCE, Sept. 1978, pp. 1443-1457.

24. F. Casciati and L. Faravelli, "Load Combination by Partial Safety Factors," Nuclear Engineering and Design, Vol. 75 (1982) pp. 432-452.

25. "Application of Reliability Methods in Design and Analysis of offshore Platforms," Journal of Structural Engineering, Oct. 1983, pp. 2265-2291. 



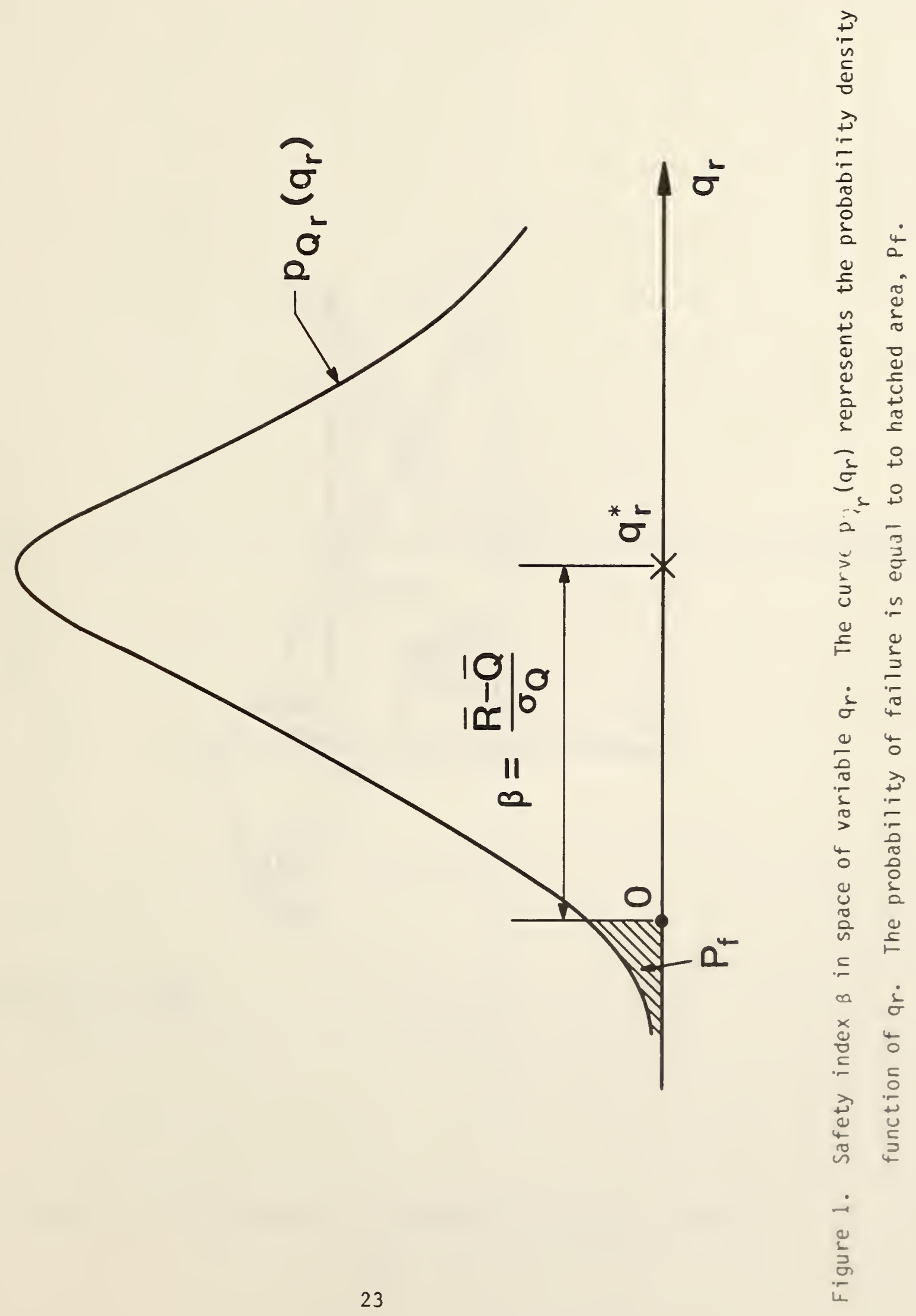




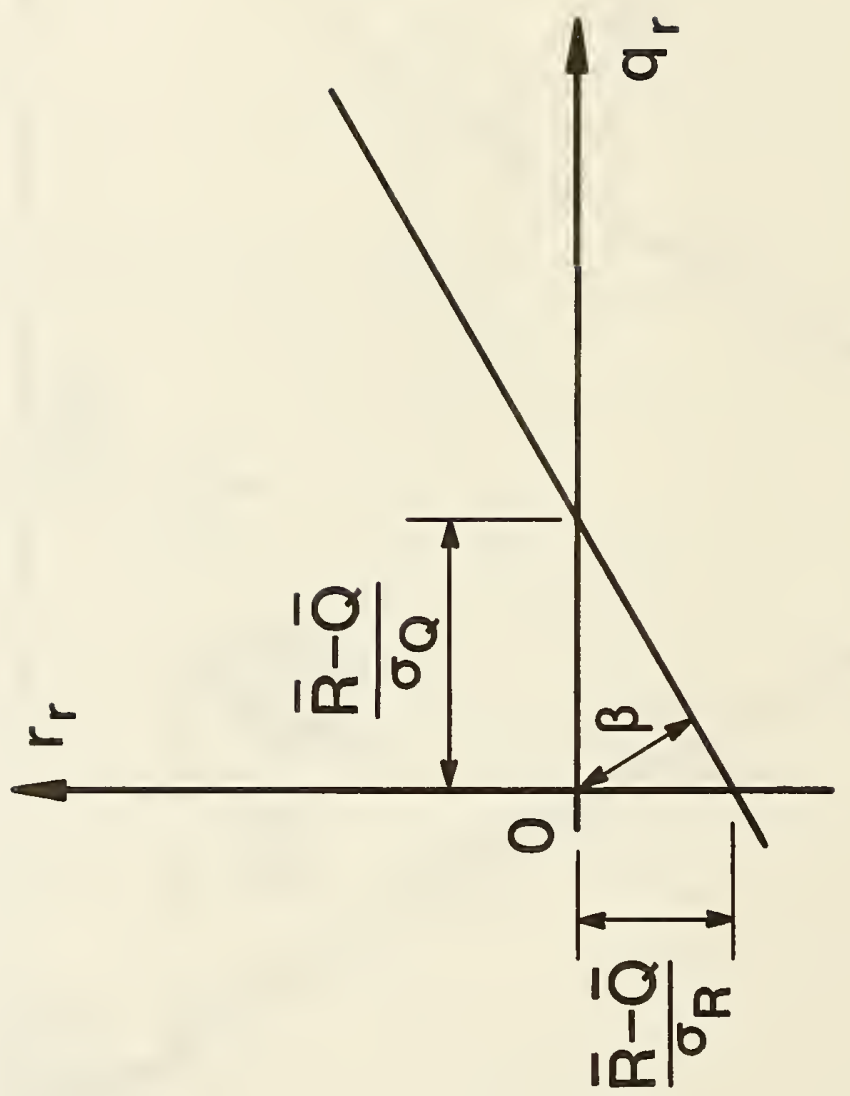

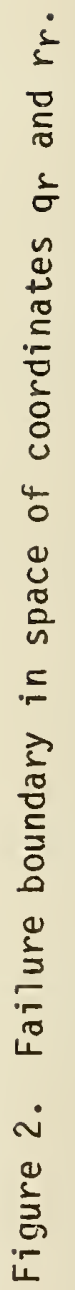




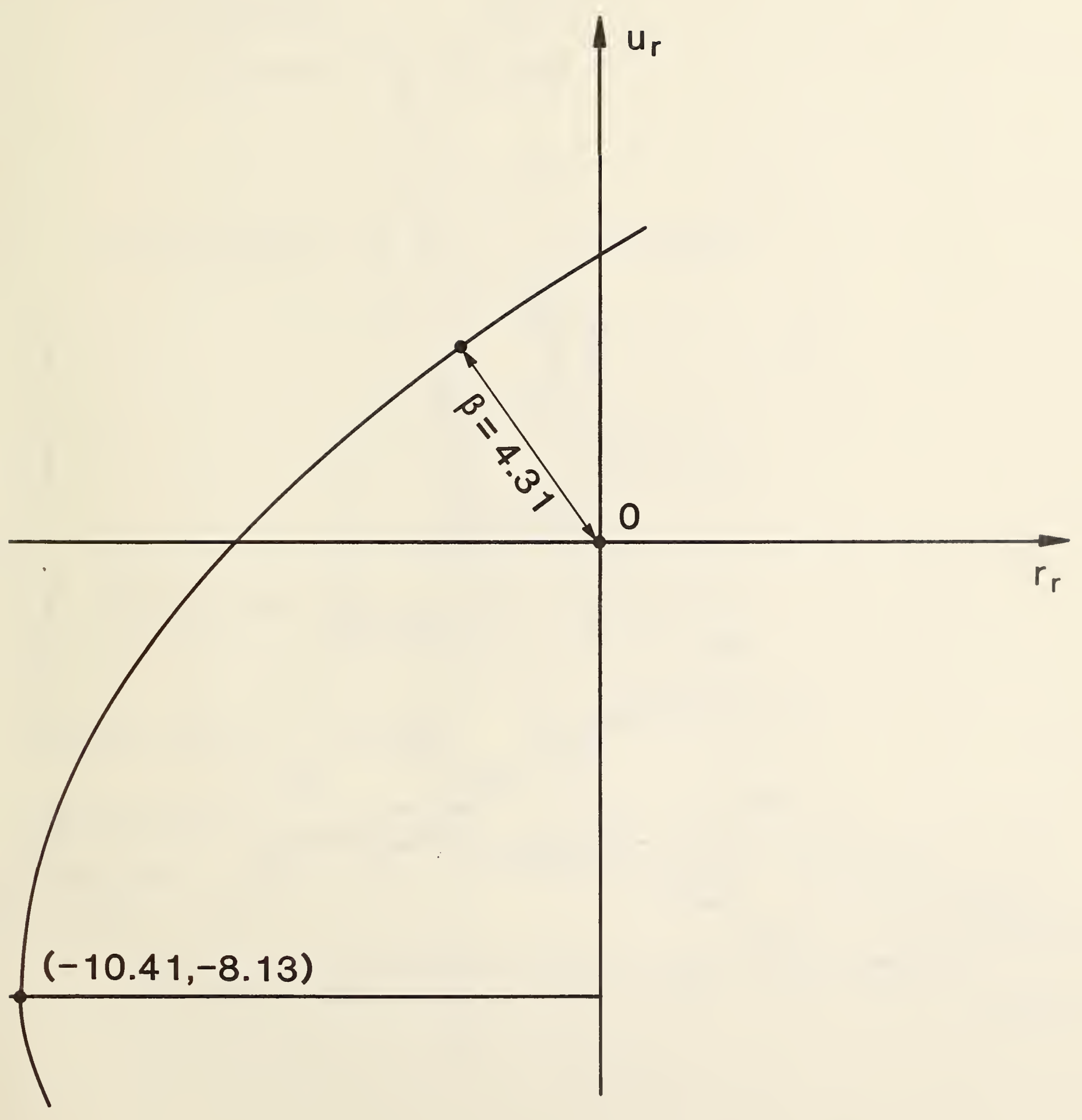

Figure 3. Failure boundary in space of coordinates $u_{r}$ and $r_{r}$ 25 


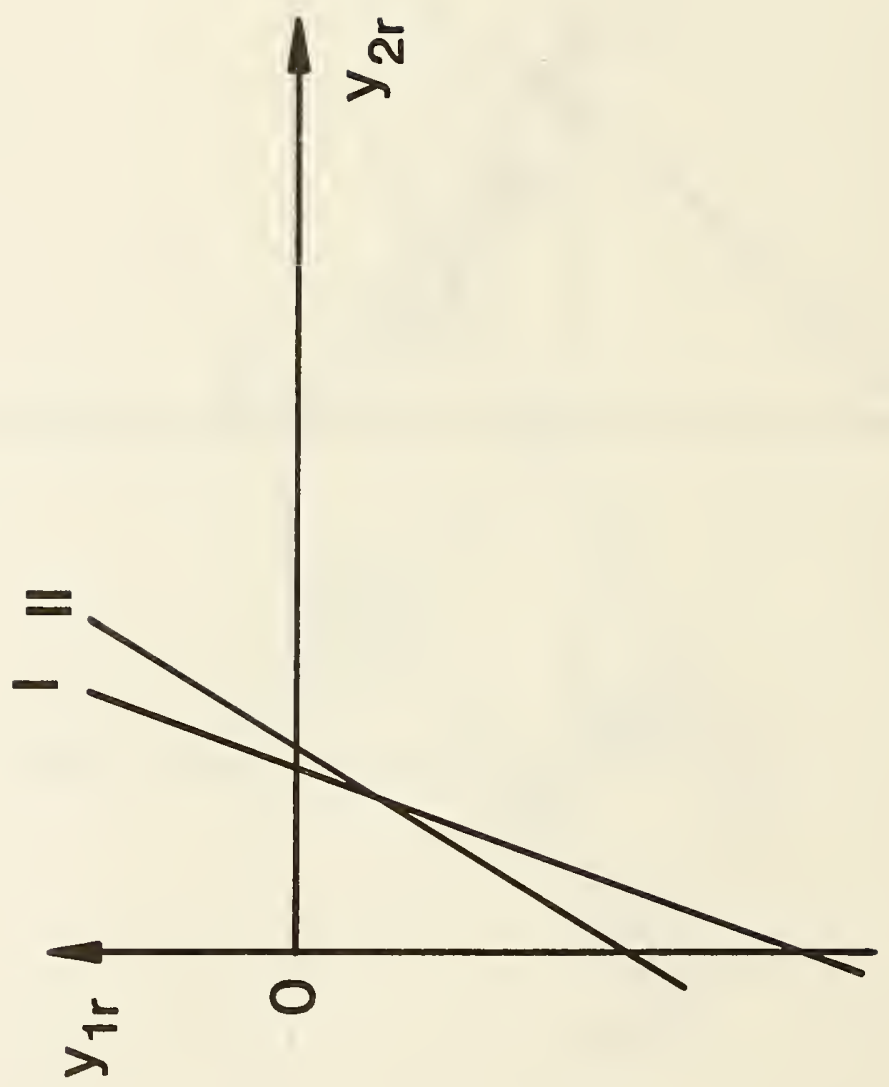


1. PUBLICATION OR REPORT NO.

BIBLIOGRAPHIC DATA

SHEET (See instructions)

4. TITLE AND SUBTITLE

Structural Reliability Fundamentals and Their Application to Offshore Structures

5. AUTHOR(S)

Emil Simiu and Charles E. Smith

6. PERFORMING ORGANIZATION (If joint or other than NBS, see instructions)

7. Contract/Grant No.

MATIONAL BUREAU OF STANDARDS

DEPARTMENT OF COMMERCE

WASHINGTON, D.C. 20234

8. Type of Report \& Period Covered

9. SFONSORHG OAGAHZATION NAMT AND COMPLETE ADORESS (StTeat, Clty, Stots, ZIP)

Minerals Management Service

Department of the Interior

Roon IP-119 USGS National Ctr. Bldg., 12203 Sunrise Valley Drive

Reston, VA 22091

10. SUPPLEMENTARY NOTES

Document describes a computer program: SF-185. FIPS Software Summary, is attached.

11. ABSTRACT (A 200-word or less factual summary of most significant information. If document includes a significant bibliography or literature survey, mention it here)

The objective of this report is to present an overview of fundamental topics in structural reliability as applied to individual members, which are potentially applicable to ocean engineering problems. These topics include: the estimation of failure probabilities; safety indices; and safety (or load and resistance) factors. Some of the theoretical and practical difficulties in the application of structural reliability tools are mentioned and/or discussed.

12. KEY WORDS (Six to twelve entries: alphabetical order: capitalize only proper names: and separate key words by semicolons) Failure; probability theory; reliability; risk; statistics; structural engineering.

\section{AVAILABILITY}

$[\bar{x}$ ] Unlimited

[ For Official Distribution. Do Not Release to NTIS

O Order From Superintendent of Documents. U.S. Government Printing Office, Washington. D.C. 20402.
14. NO. OF

PRINTED PAGES

31

15. Price

$\$ 8.50$

[X] Order From National Technical Information Service (NTIS). Springfield, VA. 22161 

